\title{
Object-based analysis of UAS imagery to map emergent and submerged invasive aquatic vegetation: a case study
}

\begin{tabular}{|r|l|}
\hline Journal: & Journal of Unmanned Vehicle Systems \\
\hline Manuscript ID & juvs-2016-0009.R1 \\
\hline Manuscript Type: & Note \\
\hline Date Submitted by the Author: & 23-Sep-2016 \\
\hline Complete List of Authors: & $\begin{array}{l}\text { Chabot, Dominique; droneMetrics } \\
\text { Dillon, Christopher; droneMetrics } \\
\text { Ahmed, Oumer; Trent University, Geomatics, Remote Sensing and Land } \\
\text { Resources Laboratory } \\
\text { Shemrock, Adam; AirTech UAV Solutions }\end{array}$ \\
\hline Keyword: & invasive species, OBIA, remote sensing, UAV, wetland monitoring \\
\hline \multicolumn{2}{|c}{} \\
\hline
\end{tabular}




\title{
Object-based analysis of UAS imagery to map emergent and submerged invasive aquatic vegetation: a case study
}

\author{
Dominique Chabot ${ }^{1}$, Christopher Dillon ${ }^{1}$, Oumer Ahmed ${ }^{2}$, and Adam Shemrock ${ }^{3}$ \\ ${ }^{1}$ droneMetrics, 7 Tauvette Street, Ottawa, Ontario, K1B 3A1, Canada \\ ${ }^{2}$ Geomatics, Remote Sensing and Land Resources Laboratory, Trent University, 1600 West \\ Bank Drive, Peterborough, Ontario, K9L 0G2, Canada \\ ${ }^{3}$ AirTech UAV Solutions, 1071 Kam Avenue, Inverary, Ontario, K0H 1X0, Canada
}

Corresponding author: Dominique Chabot (e-mail: dominique.chabot@mail.mcgill.ca) 
1 Abstract: Small unmanned aircraft systems (UAS) combined with automated image analysis

2 may provide an efficient alternative or complement to labour-intensive boat-based monitoring of

3 invasive aquatic vegetation. We trialled a small mapping drone for collecting high-resolution $(\leq 5$

$4 \mathrm{~cm} /$ pixel) true-colour and near-infrared imagery revealing the distribution of invasive water

5 soldier (Stratiotes aloides) in the Trent-Severn Waterway, Ontario (Canada). We further

6 evaluated the capacity of an object-based image analysis approach based on the Random Forests

7 classification algorithm to map features in the imagery, chiefly emergent and submerged water

8 soldier colonies. The imagery contained flaws and inconsistencies resulting from data collection

9 in suboptimal weather conditions that likely negatively impacted classification performance.

10 Nevertheless, our best-performing classification had a producer's and user's accuracy for water

11 soldier of $81 \%$ and $74 \%$, respectively, an overall accuracy of $78 \%$, and a kappa value of $61 \%$,

12 indicating "substantial" accuracy. This trial provides an instructive case study on results

13 achieved in a "real-world" application of a UAS for environmental monitoring, notably

14 characterized by time constraints for data collection and analysis. Beyond avoiding data

15 collection in unfavourable weather conditions, adaptations of the image segmentation process

16 and use of a true discrete-band multispectral camera may help to improve classification accuracy,

17 particularly of submerged vegetation.

19 Key words: image classification, invasive species, OBIA, remote sensing, UAV, wetland 20 monitoring 


\section{Introduction}

22 Water soldier (Stratiotes aloides) is an aquatic plant native to Europe and northwest Asia

23 that has become an invasive species of concern in the Trent River, Ontario (Canada), crowding

24 out native vegetation, altering water chemistry, hindering recreational activities, and injuring

25 people with its sharp serrated leaf edges (OFAH/OMNR 2012). The Ontario Ministry of Natural

26 Resources and Forestry (OMNRF) in collaboration with various partnering agencies are engaged

27 in a water soldier monitoring and control initiative focused on the Trent-Severn Waterway,

28 testing solutions such as mechanical harvesting and herbicide to eliminate the plant. Continued

29 monitoring of its extent and distribution is critical for appropriate application of control measures

30 and assessment of their effectiveness. To date, monitoring has been accomplished by means of

31 boat-based surveys, which are labour-intensive in the field. Consequently, a more convenient and

32 efficient monitoring approach would be of interest, if suitably reliable and economical.

33 Small unmanned aircraft systems (UAS) have proven useful for very high-resolution

$34(<10 \mathrm{~cm} / \mathrm{pixel})$ aerial surveys of areas and habitats that are challenging to access or navigate at

35 ground level, notably wetland (Madden et al. 2015), riverine (Birdsong et al. 2015) and aquatic

36 environments in general (Husson et al. 2014; DeBell et al. 2016; Turner et al. 2016). Moreover,

37 efforts have been invested in developing approaches to automate habitat, vegetation or land

38 cover classification in the uniquely high-resolution imagery collected by UAS, including several

39 studies focused on wetland and aquatic vegetation (Goktogan et al. 2010; Zaman et al. 2011;

40 Lechner et al. 2012; Chabot and Bird 2013; Kalacska et al. 2013; Knoth et al. 2013; Flynn and

41 Chapra 2014; Casado et al. 2015; Zweig et al. 2015). It has been noted that the fine-scale spectral

42 heterogeneity resulting from the very high resolution of UAS imagery tends to make it

43 challenging to classify using traditional pixel-based spectral classification methods, and 
44 consequently object-based image analysis (OBIA) has been advocated as a more effective 45 approach to classification (Whitehead and Hugenholtz 2014).

46 The aim of this trial study was to evaluate the effectiveness of UAS-based monitoring of

47 water soldier encroachment on the Trent-Severn Waterway, and specifically the capacity to

48 automate detection and mapping of emergent and submerged colonies in UAS imagery using

49 OBIA classification methods. A further purpose of this note is to provide an example of a "real-

50 world" application of a UAS for environmental monitoring and the results thereof, characterized

51 by time constraints, suboptimal weather conditions during data collection, and an overall

52 prioritization of efficiency over thoroughness.

\section{Materials and methods}

55 Study area

56 The trial focused on a $\sim 50$-ha shallow-water (mostly $<1 \mathrm{~m}$ ) bay $\left(44.377^{\circ} \mathrm{N}, 77.828^{\circ} \mathrm{W}\right)$ in

57 the Trent River (Fig. 1). Native aquatic vegetation occurring in the bay includes tapegrasses

58 (Hydrocharitaceae family), water/pond lilies (Nymphaeaceae family), slender naiad (Najas

59 flexilis), floating-leaf pondweed (Potamogeton natans), water crowfoot (Ranunculus family),

60 coontail (Ceratophyllum demersum), stoneworts (Characeae family), and bulrush (Scirpus spp.).

61 The bay and surrounding water bodies have been the focus of experimental water soldier control

62 treatments, and a coarse-scale map of water soldier distribution in the general area was produced

63 in 2015 (Fig. 1) by sampling the presence/absence and abundance of water soldier from a boat

64 throughout a $50 \times 50-\mathrm{m}$ grid.

65

66 Data collection 
We collected aerial imagery with an eBee "mapping drone" (senseFly, Cheseaux-

68 Lausanne, Switzerland), an 700-g UAS featuring a foam delta-winged airframe of $\sim 1-\mathrm{m}$

69 wingspan. Flights over the study area were conducted during the morning of 15 October 2015.

70 Sky conditions were partly cloudy with winds $\sim 30 \mathrm{~km} / \mathrm{h}$ gusting to $\sim 40 \mathrm{~km} / \mathrm{h}$. Two flights were

71 completed at an altitude of $137 \mathrm{~m}$ (450 ft) AGL to collect true-colour (RGB) and near-infrared

72 (NIR) imagery. RGB imagery was acquired with an 18.2-megapixel Sony Cyber-shot DSC-

73 WX220, yielding a ground sample distance (GSD) of $3.9 \mathrm{~cm} /$ pixel. NIR imagery was acquired

74 with a 12-megapixel Canon PowerShot S110 modified to capture NIR, yielding a GSD of 5.4

$75 \mathrm{~cm} /$ pixel. Each camera captured 253 photos with $70 \%$ forward and lateral overlap. We then post-

76 processed photos into orthomosaics using Postflight Terra 3D v4.0 (senseFly). Georeferencing

77 was based on the aircraft's GPS data in combination with data recorded by the autopilot's inertial

78 measurement unit to correct for angular offsets. We subsequently re-referenced the NIR imagery

79 directly to the RGB imagery to improve the alignment of the orthomosaics ahead of their

80 combined use in OBIA.

81 Additionally, ground truthing was carried out in the bay on 2 November 2015 to provide

82 image classification training data. A series of GIS polygons were first drawn around clearly

83 discernible submerged and emergent vegetation colonies in the RGB orthomosaic, to which

84 surveyors then navigated by boat and recorded the dominant vegetation type. A total of 92

85 samples were collected in this manner.

86

87 Image classification

88 Following the OBIA approach, we first performed multi-resolution image segmentation

89 using the ENVI v5.1 (Exelis, Boulder, CO, USA) Feature Extraction module on a combination of 
90 the RGB bands and the NIR band, with a scale level of 78 and merge level of 95, resulting in

91100,433 image objects of varying size and shape throughout the area of the bay. We then

92 classified the segmented objects using the Random Forests (RF) algorithm (Breiman 2001), a

93 "machine learning" approach to image classification based on inputting training samples, as

94 opposed to manually developing an object classification rule set. RF is known to be particularly

95 efficient when dealing with large numbers of input variables, and has previously been employed

96 to classify high-resolution UAS imagery (Kelcey and Lucieer 2013; Feng et al. 2015; Ma et al.

97 2015; Gonçalves et al. 2016). Since the ground-truth samples were often clustered and not

98 distributed throughout the study area, we merely used them to initially develop familiarity with

99 the appearance of various vegetation types in the imagery. We then selected representative

100 training samples (i.e. image objects) throughout the study area based on visual interpretation of

101 the imagery (Chabot and Bird 2013; Zweig et al. 2015), defining the following four classes: (1)

102 emergent water soldier; (2) submerged water soldier; (3) native vegetation; (4) other. In an effort

103 to evaluate whether the number of inputted training samples affects classification accuracy, we

104 performed a classification based on 130 training samples (minimum of 30 per class) as well as a

105 classification based on half of the training samples (65), selected at random.

106

107 Classification assessment

108 We evaluated classification accuracy by generating 400 randomly placed points

109 throughout the imagery, which we manually classified based on visual interpretation and in turn

110 compared to the automated RF classifications. For both RF classifications (65 and 130 training

111 samples), we constructed a confusion matrix in relation to the manual classification and 
112 calculated standard accuracy metrics, namely the producer's accuracy (PA), the user's accuracy

113 (UA), the overall accuracy (OA), and the kappa statistic.

\section{Results}

116 The overall highest accuracy was achieved in the RF classification based on 65 training

117 samples, and a side-by-side comparison of this classified image of the study area to a composite

118 image of the raw RGB and NIR bands is shown in Fig. 2. The overall accuracy (73.50\%) and 119 kappa value (55.23\%) of the 65-training-sample classification (Table 1) were marginally higher 120 than those of the 130-training-sample classification $(\mathrm{OA}=69.50 \%$, kappa $=47.15 \%)($ Table 2$)$.

121 According to Sim and Wright (2005), these kappa values are indicative of "moderate" agreement $122(\leq 0 \%=$ poor $; 1-20 \%=$ slight; $21-40 \%=$ fair $; 41-60 \%=$ moderate $; 61-80 \%=$ substantial; $81-$ $123 \quad 100 \%=$ almost perfect). The superior performance of the former classification was mainly driven 124 by more accurate classification of submerged water soldier, although overall both classifications 125 struggled with this class compared to the others (Tables 1, 2). Both classifications also 126 undermapped native vegetation $(\mathrm{PA}=35.29-36.76 \%$ ), although points classified as such were 127 mostly correct $(\mathrm{UA}=78.13-82.76 \%)$.

128 Since submerged and emergent water soldier tended to be misclassified as one another, 129 merging these two classes in the 65-training-sample classification (Table 3 ) resulted in a higher 130 accuracy for the unified water soldier class $(\mathrm{PA}=81.13 \%$, UA $=74.14 \%)$ than either the 131 submerged or emergent class when considered separately, as well as a higher overall accuracy 132 (78.25\%) and kappa value (60.62\%), just about crossing the threshold to "substantial" agreement. 133

\section{Discussion}


Overall, the eBee UAS combined with the RF/OBIA classification approach proved

136 promising for mapping invasive water soldier, although it is likely that the particularly windy

137 conditions during data collection negatively affected image classification performance in this

138 trial. Close examination of the imagery revealed variation in water surface perturbation

139 throughout the orthomosaics — ranging from calm to light ripples, waves and white caps - that

140 may have hindered classification of submerged vegetation. Furthermore, certain portions of the

141 imagery were blurrier, likely the result of photos being captured as the lightweight aircraft was

142 being jostled by gusts. This would tend to distort image texture information used by the

143 classification algorithm. Whereas most previous studies involving classification of aquatic

144 vegetation in UAS imagery—some reporting overall accuracies $\geq 90 \%$ and kappa values $\geq 80 \%$ -

145 were carried out in the context of academic research where there is generally more flexibility to

146 plan for data collection under ideal conditions, our trial provides an instructive case study on the

147 potential consequences of more urgent data collection in the context of a work contract where

148 there was concern over the dwindling vegetation season.

149 A compounding challenge we faced was that of performing a single classification across

150 our entire relatively large image set (only cropping out areas outside the bay itself), in contrast to

151 several previous studies that either only classified a small portion of the collected imagery and/or

152 divided imagery into multiple subsets, each subject to an independent classification that limited

153 the degree of imagery variation encountered by any individual classification (Lechner et al. 2012;

154 Chabot and Bird 2013; Kalacska et al. 2013). Also, few studies have specifically involved

155 automated classification of submerged vegetation in UAS imagery. Casado et al. (2015) similarly

156 struggled to classify submerged vegetation, with a producer's accuracy of $29 \%$ despite an overall

157 classification accuracy of $81 \%$. Flynn and Chapra (2014) achieved a classification accuracy of $92 \%$ 
158 for submerged Cladophora along a 1-km stretch of a shallow non-turbid river, although the river

159 was virtually devoid of any other types of vegetation, and thus only two classes were defined:

160 "Cladophora" and "background".

161 Another apparent cause of poor classification accuracy for submerged water soldier was

162 under-segmentation of deeper water areas containing submerged vegetation compared to areas of

163 emergent vegetation, likely resulting from the dampened spectral contrasts and saturation of

164 submerged features to which the segmentation process was not as sensitive. A potential

165 workaround without in turn over-segmenting areas of emergent vegetation might be to perform

166 an additional hierarchically "nested" segmentation (Benz et al. 2004) of objects in deeper areas

167 only, then re-merge these with the rest of the objects from the initial segmentation. Imagery

168 collected with a true discrete-band multispectral camera may also yield better vegetation

169 segmentation and classification results. More sophisticated analytical methods of deriving

170 submerged vegetation depth and properties from low-altitude optical imagery have been

171 demonstrated (Visser et al. 2015), but employing these would ultimately significantly reduce the

172 efficiency of UAS-based water soldier monitoring compared to traditional boat-based surveys.

173 The fact that the 130-training-sample classification did not outperform the 65-training-

174 sample classification seems to suggest that only a modest number of training samples may be

175 required to achieve an optimal RF classification, so long as they collectively capture a sufficient

176 amount of intra- and inter-class variation. However, more rigorous testing is required to

177 substantiate this conclusion, for example repeatedly running the RF algorithm on different

178 randomly selected subsets of training samples, and experimenting with different numbers of trees

179 and/or depths in the algorithm parameters. Due to the expeditious nature of this trial, expanded

180 testing of this sort was beyond the scope of our objectives. Finally, although it is convenient that 
181 UAS imagery classification is not as reliant on ground truthing as coarser-resolution traditional

182 aerial imagery, it may always be desirable to collect at least some ground data to help familiarize

183 the interpreter with the appearance of different feature classes in the imagery and provide

184 definitive validation of classification results.

\section{Acknowledgements}

This trial was conceived, designed and funded by the Aviation, Forest Fire and

thank C. Sallaway (OMNRF), A. Brunet (AFFES - OMNRF) and the Ontario Federation of

Anglers and Hunters for collecting the ground truth data, as well as the owners of the land

191 adjacent to the study area for allowing us to deploy the UAS from their property. UAS flights

192 were authorized by a Special Flight Operations Certificate (ATS-15-16-00043103) issued by

193 Transport Canada.

194

195 References

196 Benz, U.C., Hofmann, P., Willhauck, G., Lingenfelder, I., and Haynen, M. 2004. Multiresolution, object-oriented fuzzy analysis of remote sensing data for GIS-ready information. ISPRS Journal of Photogrammetry and Remote Sensing. 58: 239-258.

199 Birdsong, T.W., Bean, M., Grabowski, T.B., Hardy, T.B., Heard, T., Holdstock, D., Kollaus, K., Magnelia, S., and Tolman, K. 2015. Application and utility of a low-cost unmanned aerial system to manage and conserve aquatic resources in four Texas rivers. Journal of the Southeastern Association of Fish and Wildlife Agencies. 2: 80-85. 
204 Casado, M.R., Gonzalez, R.B., Kriechbaumer, T., and Veal, A. 2015. Automated identification 205 of river hydromorphological features using UAV high resolution aerial imagery. Sensors. 15: 27969-27989.

207 208

Chabot, D., and Bird, D.M. 2013. Small unmanned aircraft: precise and convenient new tools for surveying wetlands. Journal of Unmanned Vehicle Systems. 1: 15-24.

DeBell, L., Anderson, K., Brazier, R.E., King, N., and Jones, L. 2016. Water resource management at catchment scales using lightweight UAVs: current capabilities and future perspectives. Journal of Unmanned Vehicle Systems. 4: 7-30.

Feng, Q., Liu, J., and Gong, J. 2015. UAV remote sensing for urban vegetation mapping using Random Forest and texture analysis. Remote Sensing. 7: 1074-1094.

Flynn, K.F., and Chapra, S.C. 2014. Remote sensing of submerged aquatic vegetation in a shallow non-turbid river using an unmanned aerial vehicle. Remote Sensing. 6: 1281512836.

Goktogan, A.H., Sukkarieh, S., Bryson, M., Randle, J., Lupton, T., and Hung, C. 2010. A rotarywing unmanned air vehicle for aquatic weed surveillance and management. Journal of Intelligent and Robotic Systems. 57: 467-484.

Gonçalves, J., Henriques, R., Alves, P., Sousa-Silva, R., Monteiro, A.T., Lomba, A., Marcos, B., and Honrado, J. 2016. Evaluating an unmanned aerial vehicle-based approach for assessing habitat extent and condition in fine-scale early successional mountain mosaics. Applied Vegetation Science. 19: 132-146.

Husson, E., Hagner, O., and Ecke, F. 2014. Unmanned aircraft systems help to map aquatic vegetation. Applied Vegetation Science. 17: 567-577. 
226 Kalacska, M., Arroyo-Mora, J.P., de Gea, J., Snirer, E., Herzog, C., and Moore, T.R. 2013.

227 Videographic analysis of Eriophorum vaginatum spatial coverage in an ombotrophic bog.

228 Remote Sensing. 5: 6501-6512.

229 Kelcey, J., and Lucieer, A. 2013. An adaptive texture selection framework for ultra-high resolution UAV imagery. Proceedings of the IEEE International Geoscience and Remote Sensing Symposium, 21-26 July 2013, Melbourne, Australia. pp. 3883-3886.

232 Knoth, C., Klein, B., Prinz, T., and Kleinebecker, T. 2013. Unmanned aerial vehicles as innovative remote sensing platforms for high-resolution infrared imagery to support restoration monitoring in cut-over bogs. Applied Vegetation Science. 16: 509-517.

Lechner, A.M., Fletcher, A., Johansen, K., and Erskine, P. 2012. Characterising upland swamps using object-based classification methods and hyper-spatial resolution imagery derived from an unmanned aerial vehicle. ISPRS Annals of the Photogrammetry, Remote Sensing

Ma, L., Cheng, L., Li, M., Liu, Y., and Ma, X. 2015. Training set size, scale, and features in geographic object-based image analysis of very high resolution unmanned aerial vehicle

242 Madden, M., Jordan, T., Bernades, S., Cotten, D.L., O’Hare, N., and Pasqua, A. 2015. 243 Unmanned aerial systems and structure from motion revolutionize wetlands mapping. In 244 Remote Sensing of Wetlands: Applications and Advances. Edited by R.W. Tiner, M.W. 245 Lang, and V.V. Klemas. CRC Press/Taylor \& Francis Group, Boca Raton, FL, USA. pp. $246 \quad 195-219$. 
247 OFAH/OMNR (Ontario Federation of Anglers and Hunters/Ontario Ministry of Natural 248 Resources). 2012. Water soldier. Invading Species Awareness Program. Retrieved online from: http://www.invadingspecies.com/invaders/plants-aquatic/water-soldier/

250 Sim, J., and Wright, C.C. 2005. The kappa statistic in reliability studies: use, interpretation, and sample size requirements. Physical Therapy. 85: 257-268.

252 Turner, I.L., Harley, M.D., and Drummond, C.D. 2016. UAVs for coastal surveying. Coastal $253 \quad$ Engineering. 114: 19-24.

254 Visser, F., Buis, K., Verschoren, V., and Meire, P. 2015. Depth estimation of submerged aquatic 255 vegetation in clear water streams using low-altitude optical remote sensing. Sensors. 15: $256 \quad 25287-25312$.

257 Whitehead, K., and Hugenholtz, C.H. 2014. Remote sensing of the environment with small 258 unmanned aircraft systems (UASs), part 1: a review of progress and challenges. Journal of Unmanned Vehicle Systems. 2: 69-85

260 Zaman, B., Jensen, A.M., and McKee, M. 2011. Use of high-resolution multispectral imagery acquired with an autonomous unmanned aerial vehicle to quantify the spread of an invasive wetland species. Proceedings of the IEEE International Geoscience and Remote systems to delineate fine-scale wetland vegetation communities. Wetlands. 35: 303-309. 
Table 1. Confusion matrix of the 65-training-sample automated classification of UAS imagery (rows) in relation to manual interpretation of the imagery (columns) for mapping invasive emergent and submerged water soldier in the Trent-Severn Waterway, Ontario (Canada).

\begin{tabular}{clllllll}
\hline & $\begin{array}{l}\text { Em. water } \\
\text { soldier }\end{array}$ & $\begin{array}{l}\text { Sub. water } \\
\text { soldier }\end{array}$ & $\begin{array}{l}\text { Native } \\
\text { vegetation }\end{array}$ & Other & Total & $\begin{array}{l}\text { User's } \\
\text { accuracy }\end{array}$ & $\begin{array}{l}\text { Commission } \\
\text { error }\end{array}$ \\
\hline $\begin{array}{c}\text { Em. water } \\
\text { soldier }\end{array}$ & 38 & 9 & 3 & 4 & 54 & $70.37 \%$ & $29.63 \%$ \\
$\begin{array}{c}\text { Sub. water } \\
\text { soldier }\end{array}$ & 10 & 29 & 10 & 13 & 62 & $46.77 \%$ & $53.23 \%$ \\
$\begin{array}{c}\text { Native } \\
\text { vegetation }\end{array}$ & 0 & 0 & 25 & 7 & 32 & $78.13 \%$ & $21.87 \%$ \\
Other & 4 & 16 & 30 & 202 & 252 & $80.16 \%$ & $19.84 \%$ \\
$\begin{array}{c}\text { Total } \\
\text { Producer's }\end{array}$ & 52 & 54 & 68 & 226 & 400 & & \\
$\begin{array}{c}\text { accuracy } \\
\text { Omission } \\
\text { error }\end{array}$ & $73.08 \%$ & $53.70 \%$ & $36.76 \%$ & $89.38 \%$ & & $\begin{array}{l}\text { Overall } \\
\text { accuracy }\end{array}$ & $\mathbf{7 3 . 5 0 \%}$ \\
\hline
\end{tabular}


Table 2. Confusion matrix of the 130-training-sample automated classification of UAS imagery (rows) in relation to manual interpretation of the imagery (columns) for mapping invasive emergent and submerged water soldier in the Trent-Severn Waterway, Ontario (Canada).

\begin{tabular}{llllllll}
\hline & $\begin{array}{l}\text { Em. water } \\
\text { soldier }\end{array}$ & $\begin{array}{l}\text { Sub. water } \\
\text { soldier }\end{array}$ & $\begin{array}{l}\text { Native } \\
\text { vegetation }\end{array}$ & Other & Total & $\begin{array}{l}\text { User's } \\
\text { accuracy }\end{array}$ & $\begin{array}{l}\text { Commission } \\
\text { error }\end{array}$ \\
\hline $\begin{array}{c}\text { Em. water } \\
\text { soldier }\end{array}$ & 34 & 7 & 2 & 3 & 46 & $73.91 \%$ & $26.09 \%$ \\
$\begin{array}{c}\text { Sub. water } \\
\text { soldier }\end{array}$ & 14 & 18 & 11 & 16 & 59 & $30.51 \%$ & $69.49 \%$ \\
$\begin{array}{c}\text { Native } \\
\text { vegetation }\end{array}$ & 0 & 0 & 24 & 5 & 29 & $82.76 \%$ & $17.24 \%$ \\
Other & 4 & 29 & 31 & 202 & 266 & $75.94 \%$ & $24.06 \%$ \\
$\begin{array}{c}\text { Total } \\
\text { Producer's }\end{array}$ & 52 & 54 & 68 & 226 & 400 & & \\
$\quad$ accuracy & $65.38 \%$ & $33.33 \%$ & $35.29 \%$ & $89.38 \%$ & & $\begin{array}{l}\text { Overall } \\
\text { accuracy }\end{array}$ & $\mathbf{6 9 . 5 0 \%}$ \\
$\begin{array}{c}\text { Omission } \\
\text { error }\end{array}$ & $34.62 \%$ & $66.67 \%$ & $64.71 \%$ & $10.62 \%$ & & Kappa & $\mathbf{4 7 . 1 5 \%}$ \\
\hline
\end{tabular}


Table 3. Confusion matrix of the 65-training-sample automated classification of UAS imagery (rows) in relation to manual interpretation of the imagery (columns) for mapping invasive water soldier (with emergent and submerged classes merged) in the Trent-Severn Waterway, Ontario (Canada).

\begin{tabular}{lllllll}
\hline & $\begin{array}{l}\text { Water } \\
\text { soldier }\end{array}$ & $\begin{array}{l}\text { Native } \\
\text { vegetation }\end{array}$ & Other & Total & $\begin{array}{l}\text { User's } \\
\text { accuracy }\end{array}$ & $\begin{array}{l}\text { Commission } \\
\text { error }\end{array}$ \\
\hline $\begin{array}{c}\text { Water } \\
\text { soldier }\end{array}$ & 86 & 13 & 17 & 116 & $74.14 \%$ & $25.86 \%$ \\
$\begin{array}{c}\text { Native } \\
\text { vegetation }\end{array}$ & 0 & 25 & 7 & 32 & $78.13 \%$ & $21.87 \%$ \\
Other & 20 & 30 & 202 & 252 & $80.16 \%$ & $19.84 \%$ \\
$\begin{array}{c}\text { Total } \\
\text { Producer's } \\
\text { accuracy }\end{array}$ & 106 & 68 & 226 & 400 & & \\
$\begin{array}{c}\text { Omission } \\
\text { error }\end{array}$ & $81.13 \%$ & $36.76 \%$ & $89.38 \%$ & & $\begin{array}{l}\text { Overall } \\
\text { accuracy }\end{array}$ & $\mathbf{7 8 . 2 5 \%}$ \\
\hline
\end{tabular}


Fig. 1. Map of invasive water soldier distribution in 2015 in the Lake Seymour area, Ontario (Canada), estimated by means of boat-based surveys (produced by the Ontario Ministry of Natural Resources and Forestry; (C) Queen's Printer for Ontario 2015). Red zones = dense colonies; beige zones $=$ scattered plants; yellow zones $=$ single plants; black rectangle $=$ study area where UAS aerial imagery was collected.

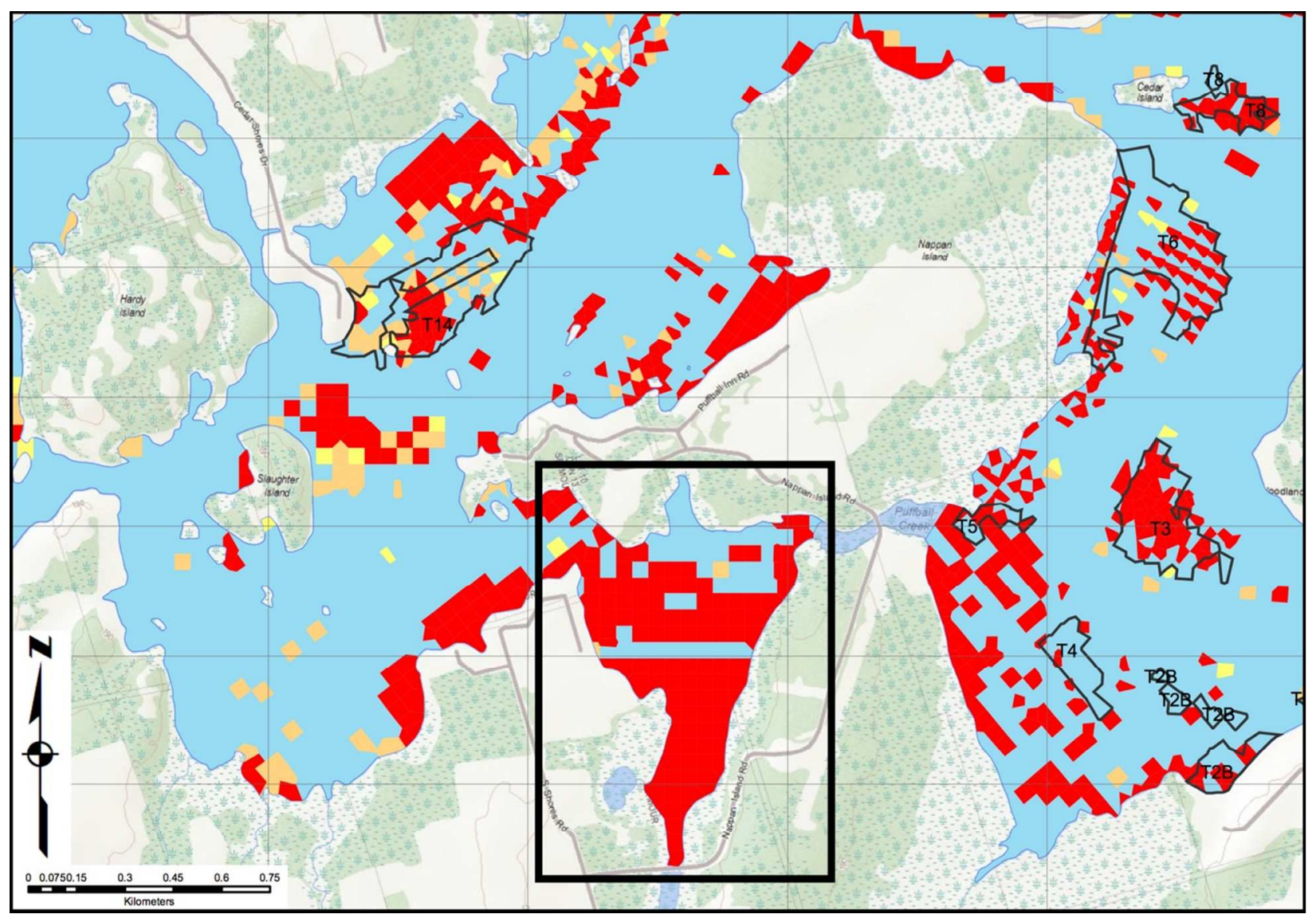


Fig. 2. Composite true-colour and near-infrared UAS imagery (left) of the bay study area in the Trent-Severn Waterway, Ontario (Canada), and 65-training-sample classified image (right). Red zones $=$ emergent water soldier; beige zones $=$ submerged water soldier; green zones $=$ native vegetation, blue zones $=$ other.

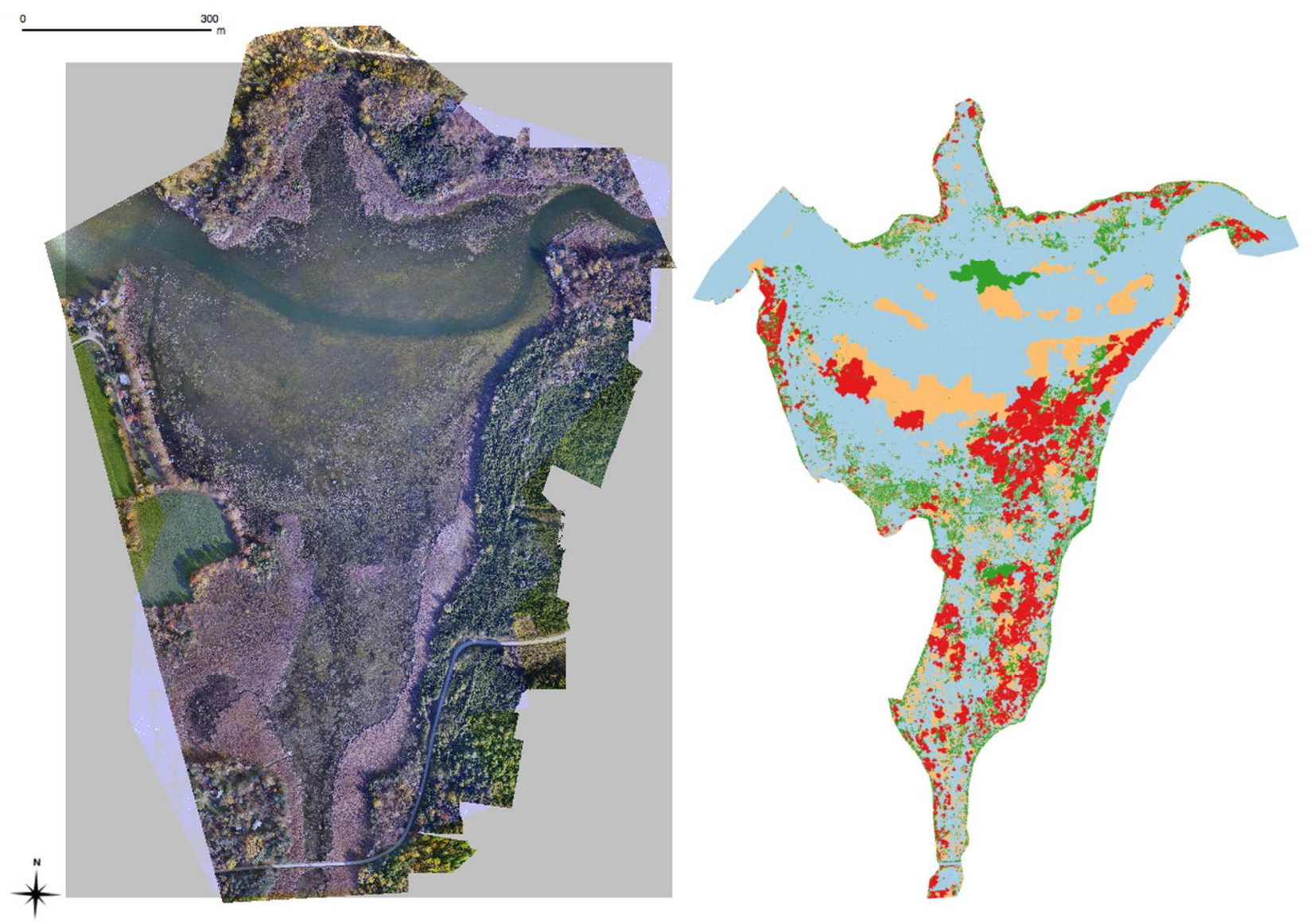

